\title{
9.4 Системний підхід до автоматизованого вибору раціональної посадки 3 натягом на основі математичного моделювання
}

У машинобудівній галузі проблема підвищення надійності механізмів і агрегатів машин є дуже актуальною. Рішення цієї проблеми пов'язане 3 підвищенням автоматизації та ефективності проектування і виробництва виробів, їх технічного рівня (технологія CAE/CAD/CAM). У сучасній техніці широко застосовуються посадки 3 гарантованим натягом, які $\epsilon$ одними 3 найбільш поширених видів умовно роз'ємних з’єднань. Від правильного вибору посадок при проектному розрахунку їх параметрів забезпечується задана міцність і надійність машин і механізмів, в яких вони застосовуються. Існуючі методи автоматизації розрахунку і вибору посадок з натягом засновані на традиційних методах прецедентів і подоби, що зазвичай грунтуються на виробничому досвіді. В деяких випадках необхідно проведення експериментальних досліджень, а також введення поправок і кореляції розрахунків. Такий підхід залежить від суб'єктивного фактору (кваліфікації і досвіду проектувальника), тому він не завжди дозволяє отримати гарантоване раціональне проектне рішення, що обране зі скінченої множини допустимих альтернативних варіантів.

Мета дослідження представленої роботи полягає у створенні ефективного методу вибору посадки 3 натягом на основі математичної моделі області існування раціональних посадок, в якій визначено і враховується комплексний взаємовплив параметрів з'єднання та використано для аналітичного опису елементів моделі математичний апарат теорії $R$-функцій [571].

В результаті проведеної авторами серії досліджень [572-578] розроблено принципово новий системний підхід до автоматизованого розрахунку і вибору посадок з натягом різного функціонального призначення. На базі такого підходу створено метод, який реалізовано у вигляді авторської комп'ютерної програми Interference Fit [579] автоматизованого розрахунку і вибору посадок з натягом (інструментальний засіб досліджень). Структура розробленої програми враховує задану систематизацію факторів обмежень [572], що значно підвищує 
продуктивність процесу проектування. За допомогою програмного забезпечення [579] користувач отримує перелік спроектованих стандартних посадок з натягом (скінчену множину проектних рішень), які відповідають певним умовам міцності і надійності та залежать від навантаження, експлуатації та системи обмежень. Отже проектувальнику необхідно обрати лише одне остаточне проектне рішення.

Програмний засіб Interference Fit успішно застосовано при розв'язанні конкретного прикладу гладкого з'єднання посадки 3 натягом для вінця зубчастого колеса з маточиною при термічному способі складання, виконаного за методом повної взаємозамінності при вихідних даних: осьова навантажувальна сила $F_{a}=1500 \mathrm{H}$; навантажувальний обертальний момент $T=2000 \mathrm{H} \cdot \mathrm{M}$; діаметр внутрішньої поверхні $d_{1}=50$ мм і матеріал Сталь $45 \mathrm{X}$ для охоплюваної деталі; умовний зовнішній діаметр $d_{2}=130$ мм і матеріал Сталь 50 для охоплюючої деталі; діаметр посадкового з'єднання $d=85$ мM ; робоча довжина посадкового з'єднання $l=90$ мМ.

На етапах чисельно-аналітичних досліджень при аналізі вихідних даних і низки отриманих результатів автоматизованих розрахунків побудовано графік функції $N=\mathrm{f}(p)$ [573] у координатній площині $p N$, де $p$ - питомий контактний тиск на робочі поверхні деталей, а $N$ - розрахунковий натяг (рис. 1). Допустимий максимальний тиск $\left[p_{\max }\right]$ у досліджуваному з'єднанні так само, як i величина максимального розрахункового натягу $\left[N_{\max }\right], \epsilon$ величинами сталими, за верхньою границею яких відбувається руйнування найбільш слабкої деталі. Зазначені параметри $\left[p_{\max }\right]$ i $\left[N_{\max }\right]$ мають лінійний характер і залежать від властивостей матеріалів 3'єднання. Величина мінімального питомого тиску $\left[p_{\min }\right]$, при якому забезпечується невихід деформацій деталей з'єднання за границі пружності, суттєво залежить від робочої довжини $l$. 


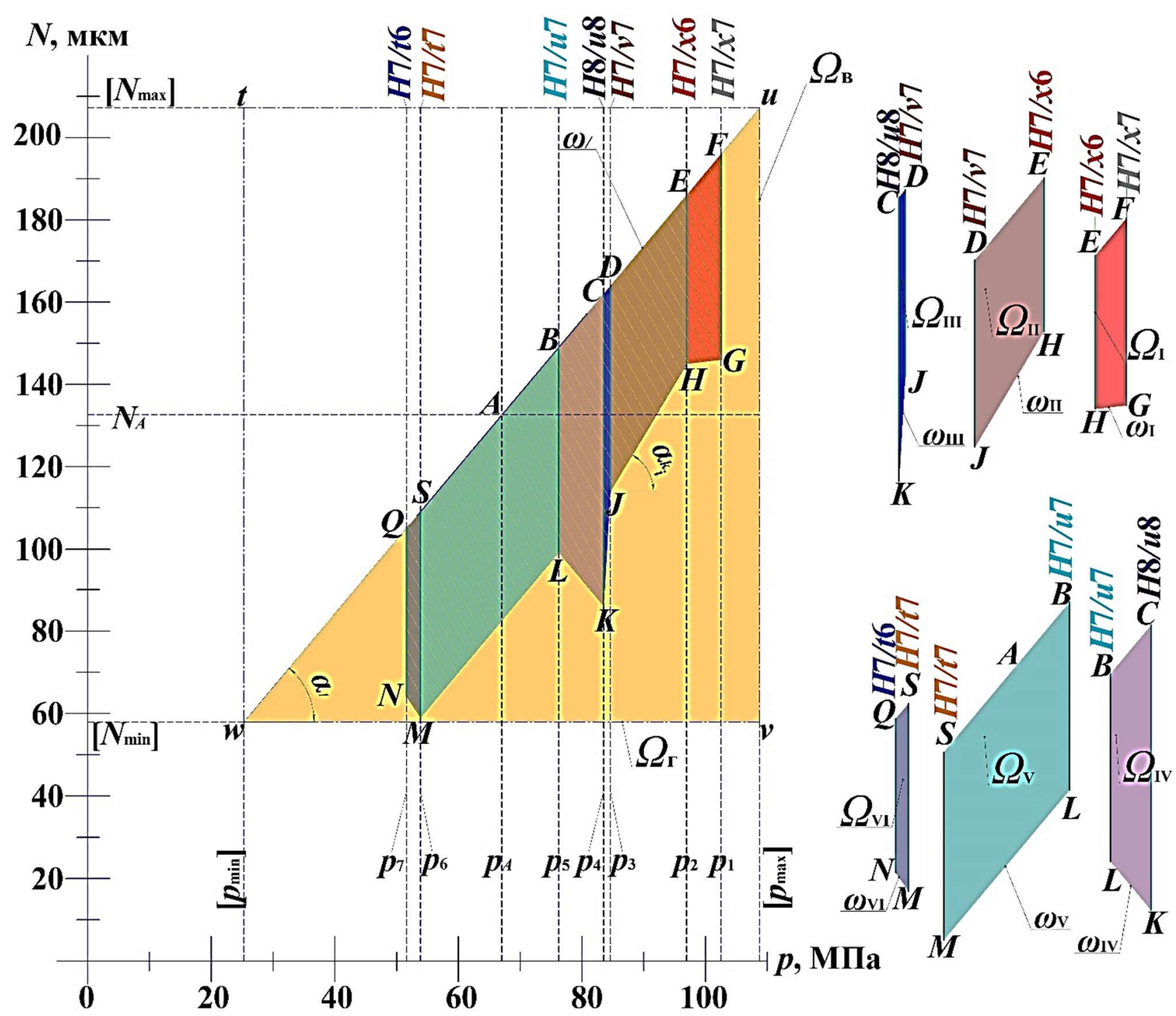

Рисунок 1. Результати дослідження ЗОВДР, ОІПСП, СМРПР і ОРПР для залежності $N=\mathrm{f}(p)$ при сталих геометричних значеннях

Очевидним є той факт, що в ідеальному випадку дійсні значення розмірів охоплюваної і охоплюючої деталей, які утворюють натяг, будуть забезпечувати значення середнього натягу $N_{\text {c }}$ при їх максимальному наближенні до деякої

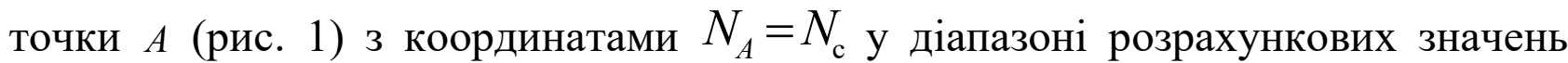
$\left[N_{\min }\right] \ldots\left[N_{\max }\right]$ i $p_{A}=p_{\text {c }}$ у діапазоні $\left[p_{\min }\right] \ldots\left[p_{\max }\right]$. Знайдені параметри $N_{A}$ i $p_{A}$ забезпечують деформації деталей у границях пружності при заданих фіксованих значеннях робочої довжини і посадкового діаметра. Сама точка $A$, яка є центром симетрії прямокутника tuvw - загальної області всіх допустимих рішень 
(ЗОВДР), являє собою центр групування раціональних сполучень питомого тиску і натягу. Для визначення таких сполучень користувач має задати $n$-ну кількість параметрів, як критеріїв, за врахуванням яких є можливість обрати одну раціональну стандартну посадку з усіх можливих придатних. Критеріями для визначення ЗОВДР є: натяги $N$ (допустимі максимальний $\left[N_{\max }\right]$ i мінімальний $\left[N_{\text {min }}\right]$; дійсний $N_{i}$ та імовірнісні максимальний $N_{\text {iмmax }_{i}}$ i мінімальний $N_{\text {iмmin }_{i}}$ для

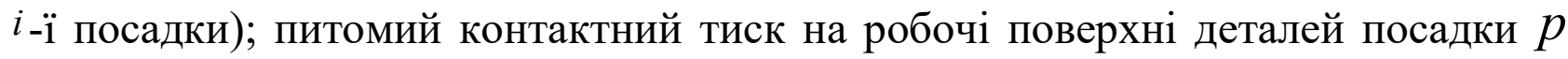
(граничні мінімальний $\left[p_{\min }\right]$ і максимальний $\left[p_{\max }\right]$, а також дійсний $p_{i}$ для $i$-ої посадки). Ці критерії суттєво залежать від геометричних посадкових параметрів - діаметра $d$ і робочої довжини $l$, а також від величин, які визначають спосіб складання: температури нагрівання охоплюючої $t_{2}$ (охолодження охоплюваної $t_{1}$ ) деталі при термічному способі або сила запресовування $F_{3}-$ при механічному.

Для більш обгрунтованого вибору остаточного проектного рішення 3 ЗОВДР за методом повної взаємозамінності при фіксованому значенні діаметра посадкового з'єднання необхідне забезпечення відповідної міцності, для якої дійсні значення питомого тиску $p_{i}$ і натягу $N_{i}$ у $i$-ій посадці відповідають граничним умовам $\left[p_{\min }\right] \leq p_{i} \leq\left[p_{\max }\right] \mathrm{i}\left[N_{\min }\right] \leq N_{i} \leq\left[N_{\max }\right]$, тобто в границях прямокутника $t u v w$ ЗОВДР, який є двопараметричною плоскою моделлю, побудованою у координатній площині $p N$. Всі раціональні рішення допустимих значень розглядуваної ЗОВДР аналітично описані за допомогою математичного апарату теорії $R$-функцій [574], застосування якого дозволяє значною мірою автоматизувати проектування посадкових з’єднань:

$$
\Omega_{\mathrm{B \Gamma}}=\Omega_{\mathrm{B}} \wedge_{0} \Omega_{\mathrm{\Gamma}},
$$

де $\wedge_{0}-$ символ $R$-кон'юнкції [571, 580-582], що означає перетин множин $\Omega_{\text {в }}, \Omega_{\text {г }} ; \Omega_{\text {в }}$ - множина допустимих значень посадок у вигляді вертикальної 
смуги (для питомого тиску $\left.\left[p_{\min }\right] \mathrm{i}\left[p_{\max }\right]\right) ; \Omega_{\text {г }}-$ множина допустимих значень посадок у вигляді горизонтальної смуги (для натягу $\left[N_{\min }\right] \mathrm{i}\left[N_{\max }\right]$ ).

Користуючись властивістю кон'юнкції, вся множина, як область допустимих значень, буде згідно з формулою (1) дорівнювати:

$$
\begin{gathered}
\Omega_{\text {вг }}=\Omega_{\mathrm{B}}+\Omega_{\mathrm{r}}-\sqrt{\Omega_{\mathrm{B}}^{2}+\Omega_{\mathrm{r}}^{2}}= \\
=\left[\left(\frac{\left[p_{\max }\right]-\left[p_{\min }\right]}{2}\right)^{2}-\left(p-p_{A}\right)^{2}\right]+\left[\left(\frac{\left[N_{\max }\right]-\left[N_{\min }\right]}{2}\right)^{2}-\left(N-N_{A}\right)^{2}\right]- \\
-\sqrt{\left[\left(\frac{\left[p_{\max }\right]-\left[p_{\min }\right]}{2}\right)^{2}-\left(p-p_{A}\right)^{2}\right]^{2}+\left[\left(\frac{\left[N_{\max }\right]-\left[N_{\min }\right]}{2}\right)^{2}-\left(N-N_{A}\right)^{2}\right]^{2}} .
\end{gathered}
$$

де $p$ i $N$-значення питомого тиску і натягу вздовж координатних осей $p$ i $N$ (див. рис. 1); $p_{A}, N_{A}$ - дійсні координати центру симетрії (точки $A$ ) прямокутника $t u v w$ у заданому перерізі (для робочої довжини $l$ ).

Слід зазначити, що у трикутнику $t w w$, який є половиною прямокутника $t u v w$ ЗОВДР (див. рис. 1), над діагоналлю $u w$ ніяких стандартних посадок не існує, тому діапазони цих придатних посадок знаходяться під діагоналлю прямокутника, тобто у трикутнику $u v w$ - області існування придатних стандартних посадок (ОІПСП). 3 цієї причини всі раціональні рішення слід обмежити ще однією множиною $\omega$, - діагоналлю $u w$, яка є обмежувальною верхньою границею максимальних значень натягів $N_{\text {iмmax }_{i}}$ імовірнісного допуску стандартних посадок. В цьому випадку:

$$
\omega_{l}=p-\frac{\left[p_{\max }\right]-\left[p_{\min }\right]}{\left[N_{\max }\right]-\left[N_{\min }\right]} N+\frac{\left[p_{\max }\right]-\left[p_{\min }\right]}{2} .
$$

У підсумку всі раціональні рішення допустимих значень плоскої моделі ОІПСП у трикутнику $u v w$, позначеної множиною $\Omega_{\Delta}$ остаточно мають вигляд:

$$
\Omega_{\Delta}=\left(\Omega_{\mathrm{B}} \wedge_{0} \Omega_{\mathrm{T}}\right) \wedge_{0} \omega_{/}
$$


Для розглядуваного прикладу вся сукупність сімох стандартних придатних посадок з натягом (у вигляді ортогональних прямих відрізків) являє собою скінчену множину $\omega$, що включає $m$ раціональних проектних рішень в межах границь ОІПСП множини $\Omega_{\Delta}$. Як розвиток досліджень на основі автоматизованого розрахунку в загальному виді аналітично опишемо рівняння скінченої множини раціональних проектних рішень (СМРПР) за допомогою теорії $R$-функцій $[571,580]$ :

$$
\omega=\omega_{i} \vee_{0} \omega_{i+1} \vee_{0} \ldots \vee_{0} \omega_{m}=\omega_{1} \vee_{0} \omega_{2} \vee_{0} \omega_{3} \vee_{0} \omega_{4} \vee_{0} \omega_{5} \vee_{0} \omega_{6} \vee_{0} \omega_{7}
$$

де $\vee_{0}-$ знак $R$-диз'юнкції, що означає об'єднання множин; $m$ - скінчена множина проектних рішень (для розглядуваного прикладу $m=7$ ); $\omega_{i}-$ аналітична формула $i$-ої придатної стандартної посадки

3 цього $m$-го переліку придатних посадок СМРПР $\omega$, що входить до множини $\Omega_{\Delta}$ плоскої моделі в координатних осях $p N$, користувач має обрати одне раціональне проектне рішення. Для цієї мети авторами [575] запропоновано окреслити всю область раціональних проектних рішень (ОРПР), позначеної далі через множину $\Omega$. Вона утворена відрізками СМРПР та представляє собою для даного прикладу багатокутник $A B C D E F G H J K L M N Q S$ (див. рис. 1), тобто $\omega \in \Omega$ . Розглядуваний об'єкт $\Omega$ утворюється прямим відрізком $Q F$, що збігається 3 діагоналлю $u w$ та обмежує максимальні значення допусків ймовірнісних натягів стандартних посадок від $N_{\text {immax }_{i}}$ до $N_{\text {iмmax }_{m}}$, а ламана лінія $G H J K L M N$ багатокутника - границю їх мінімальних значень від $N_{\text {ismin }_{i}}$ до $N_{\text {iмmin }_{m}}$. Точка $A$ ділить навпіл діагональ $u w$ і знаходитися на відрізку $Q F$. Відрізок $Q N$ (допуск імовірнісного натягу стандартної посадки $H 7 / t 6$ - множина $\omega_{7}$ ) замикає лівий край багатокутника, а відрізок $F G$ (посадки $\left.H 7 / x 7-\omega_{1}\right)$ - правий.

На наступному етапі слід аналітично описати за допомогою теорії $R$ функцій $[571,581]$ всю ОРПР. Досліджувану множину $\Omega$ розіб'ємо на ряд окремих ділянок у вигляді чотирьохкутників - підмножин $\Omega_{k_{i}}, \Omega_{k_{i+1}}, \ldots, \Omega_{k_{m-1}}$ 
(для нашого прикладу $\Omega_{\text {I }}-$ ділянка $E F G H, \Omega_{\mathrm{II}}-D E H J, \Omega_{\mathrm{III}}-C D J K, \Omega_{\mathrm{IV}}-$ $B C K L, \Omega_{\mathrm{v}}-S B L M, \Omega_{\mathrm{VI}}-M N Q S$ (див. рис. 1). На основі властивостей об’єднання можна аналітично описати множину $\Omega$ у вигляді:

$$
\Omega=\Omega_{k_{i}} \vee_{0} \Omega_{k_{i+1}} \vee_{0} \ldots \vee_{0} \Omega_{k_{m-1}}=\Omega_{\mathrm{T}} \vee_{0} \Omega_{\mathrm{TI}} \vee_{0} \Omega_{\mathrm{III}} \vee_{0} \Omega_{\mathrm{TV}} \vee_{0} \Omega_{\mathrm{V}} \vee_{0} \Omega_{\mathrm{VI}},
$$

де $m-1$ - кількість ділянок (частин) загальної області $\Omega$ залежно від $m$-ої кількості варіантів посадок СМРПР; $\Omega_{k_{i}}$ - окрема ділянка загальної області $\Omega$ (у вигляді частини плоского чотирикутника) між питомими тисками $p_{i} \mathrm{i} p_{i+1}$ для $i$ -ї і $i+1$ стандартних посадок відповідно.

Аналітична формула окремої ділянки області $\Omega_{k_{i}}$ між питомими тисками $p_{i}$ i $p_{i+1}$ сусідніх придатних стандартних посадок визначається на основі властивостей перетину множин:

$$
\Omega_{k_{i}}=\omega_{0} \wedge_{0} \omega_{i} \wedge_{0} \omega_{l+1} \wedge_{0} \omega_{k_{i}}
$$

де $\omega_{k_{i}}-$ відрізки між нижніми границями $\left(\omega_{\mathrm{I}}, \omega_{\mathrm{II}}, \omega_{\mathrm{III}}, \omega_{\mathrm{IV}}, \omega_{\mathrm{V}} \mathrm{i} \omega_{\mathrm{VI}}\right)$ мінімальних значень імовірнісних натягів від $N_{\text {iмmin }}$ до $N_{\text {iмmin }_{i+1}}$ ламаної лінії $G H J K L N$ для відповідних сусідніх допусків стандартних посадок області ОРПР між питомими тисками $p_{i}$ i $p_{i+1}$.

Нижня границя мінімальних значень від $N_{\text {iмmini }_{i}}$ до $N_{\text {immin }_{m}}$ має вигляд ламаної лінії GHJKLMN багатокутника (див. рис. 1). Кожна окрема ділянка лінії представляє собою окремий похилий відрізок $\omega_{k_{i}}\left(\omega_{\mathrm{I}}-G H, \omega_{\mathrm{II}}-H J, \omega_{\text {III }}-\right.$ $J K, \omega_{\mathrm{IV}}-K L, \omega_{\mathrm{V}}-L M$ i $\left.\omega_{\mathrm{VI}}-M N\right)$ залежно від кута нахилу $\alpha_{k_{i}}$ до горизонту. Рівняння похилої прямої:

$$
\omega_{k_{i}}=p_{k} \cdot p+N_{k} \cdot N+c_{k},
$$

де $p_{k}$ i $N_{k}$ - точки перетину напрямних відрізків $\omega_{k_{i}}$ з координатними осями $p$ i $N$ відповідно, які нахилені під кутами нахилу $\alpha_{k_{i}}$ до горизонту, тобто 
$p_{k}=p_{i}-p \in$ відстанню між питомим дійсним тиском $p_{i} i$-ї посадки та початком координати $p$, а $N_{k}=N_{\text {immin }_{i}}-N$ - відстань між мінімальним імовірнісним натягом $N_{\text {immin }_{i}}$ тісї ж посадки та початком координати $N ; c_{k}$ - стала величина.

Після алгебраїчного перетворення рівняння (8) має остаточний вигляд:

$$
\omega_{k_{1}}=p+\frac{p_{k}}{N_{k}} N-p_{k}=p+N \cdot \operatorname{ctg} \alpha_{k_{i}}-p_{k} .
$$

Залежно від кута нахилу $\alpha_{k_{i}}$ до горизонту можливі випадки положення відрізка $\omega_{k_{i}}$ : для кута нахилу $\alpha_{k_{1}} \geq 180^{\circ}$ (кути $\alpha_{4}$ i $\alpha_{6}$ для напрямних відрізків $\omega_{\mathrm{IV}}$ i $\omega_{\mathrm{VI}}$ відповідно) напрямна відрізка $\omega_{k_{i}}=\omega_{k_{1}}$; для кута нахилу в діапазоні $45^{\circ} \leq \alpha_{k_{2}} \leq 90^{\circ}\left(\alpha_{2}, \alpha_{3}\right.$ i $\alpha_{5}$ для напрямних відрізків $\omega_{\mathrm{II}}, \omega_{\mathrm{III}}$ і $\omega_{\mathrm{V}}$ відповідно) $\omega_{k_{i}}=\omega_{k_{2}}$; для кута нахилу $\alpha_{k_{3}} \leq 45^{\circ}$ ( $\alpha_{1}$ для напрямного відрізка $\left.\omega_{\mathrm{I}}\right), \omega_{k_{i}}=\omega_{k_{3}}$

Можна стверджувати, що $i$-ту раціональну посадку з гарантованим натягом, параметри якої знаходяться в околицях точки $A\left(p_{i} \rightarrow p_{A}, N_{i} \rightarrow N_{A}\right)$ (див. рис. 1), можна вважати наближеною до оптимальної. Авторами $[2,3,6-8]$ запропоновано виділити навколо точки $A$ вірогідну локалізовану зону раціональних придатних посадок (ВЛЗРПП) певної форми, позначеною множиною $\omega_{\square}$, в яку повинні входити їх дійсні значення, що забезпечують посадки. Використання такої зони дозволить користувачеві значно звузити пошук з кількості альтернативних придатних посадок до доцільного мінімуму при виборі раціонального проектного рішення. Для цього має виконуватися умова ієрархічного підпорядкування: $\omega_{\square} \in \Omega \in \Omega_{\Delta} \in \Omega_{\text {вг }}$, тобто множина ВЛЗРПП входить до ОРПР, утвореної СМРПР, що вписується у границі ОІПСП, а остання $\epsilon$ частиною (половиною) ЗОВДР прямокутника $t u v w$.

Авторами за допомогою теорії $R$-функцій аналітично описано кілька варіантів форм (прямокутні, еліпсоїдні та кругові) ВЛЗРПП [6-8]. При їх порівняльному аналізі найефективнішою виявилася кругова форма 3 центром у 
точці $A$. Як один із способів відшукання раціонального проектного рішення для плоскої моделі в межах ОІПСП (трикутника $u v w$ ) в координатних осях $p N$, авторами запропоновано графоаналітичним способом окреслити всередині границь СМРПР кругову вірогідну зону навколо точки $A$ у вигляді півкруга 3 дугою $f g h$ (рис. 2) [572, 573, 578].

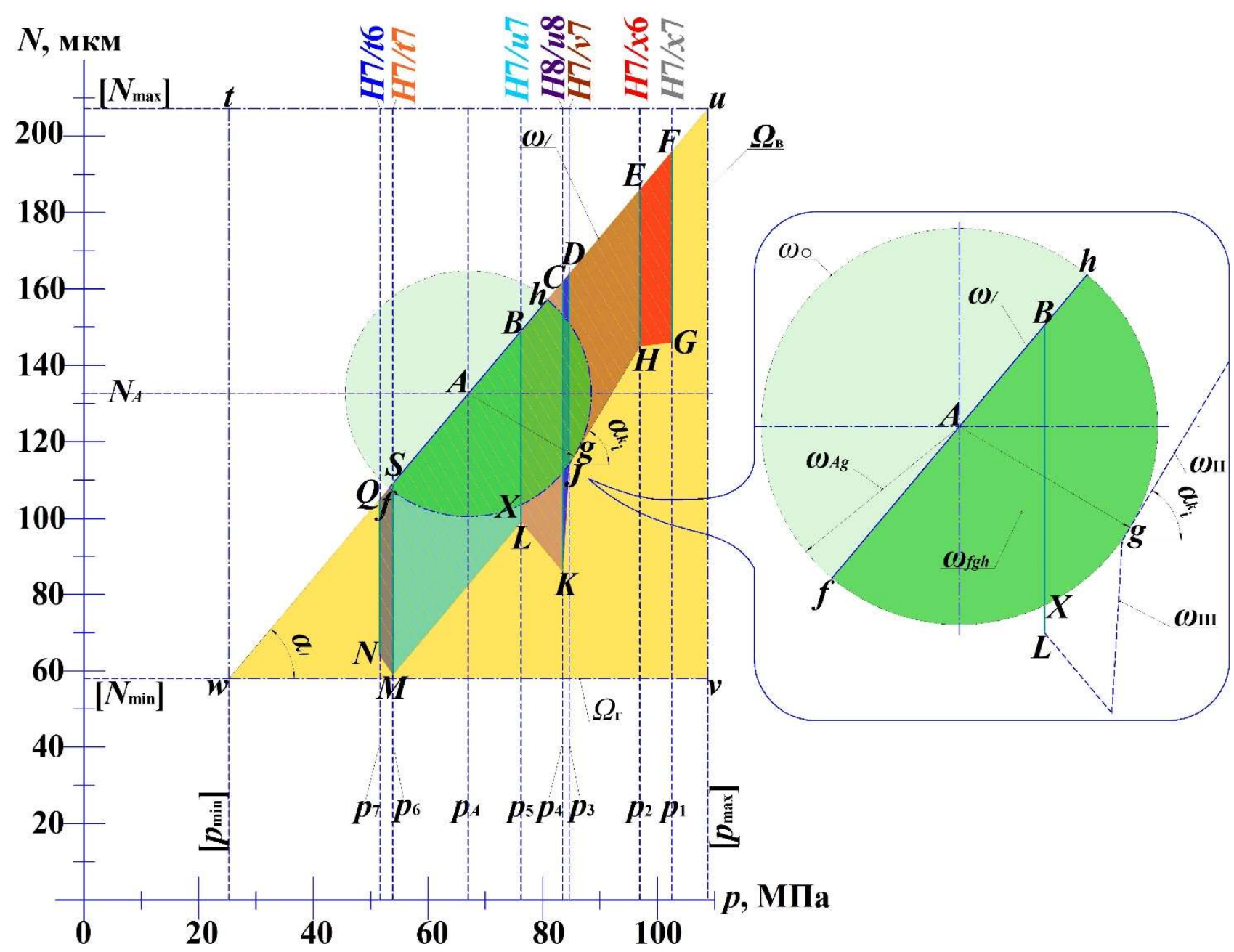

Рисунок 2. Прийнята форма вірогідної кругової зони при сталому значенні діаметра $d$ і дискретному значенні довжини $l_{k}$

Півкруг ВЛЗРПП торкається до ламаної лінії $G H J K L M N$, у точці $g$, що належить найближчому відрізку $H J$ (множина $\omega_{\text {II }}$ ) між сусідніми точками $H$ i $J$. Точка $J$ також належить відрізку $D J$ імовірнісного допуску посадки $H 7 / v 7$ , а $H$ - відрізку $E H$ посадки $H 7 / x 6$. Між точками $A$ i $g$ утворюється радіус 
$R=A g$ (точка $g$ є точкою перетину відрізків $A g$ і $H J$, причому $A g \perp H J$ ), яким описується зона півкруга 3 дугою $f g h$ для вибору раціонального проектного рішення. Для опису положення розташування радіусу $R$ за допомогою $R$-функцій необхідно вирішити систему рівнянь: рівняння відрізку $H J$, позначеного $\omega_{\text {II }}$ та рівняння відрізку $A g$, що позначимо $\omega_{A g}$. Для відрізку $\omega_{\text {II }}$, напрямок якого збігається 3 похилою прямою $\omega_{k_{i}}(9)$, відомі координати $p_{i}, N_{\text {iмmin }_{i}}$ i $p_{i+1}, N_{\text {iмmin }_{i+1}}$, зокрема для нашого прикладу - в точках $H\left(p_{2}, N_{\text {immin }_{2}}\right)$ і $J\left(p_{3}, N_{\text {immin }_{3}}\right)$. Оскільки натяг є функцією, що залежить від аргументу питомого тиску з'єднання, тобто $N=\mathrm{f}(p)$, то рівняння похилої прямої в системі координат $p N$ має вид:

$$
N=a \cdot p+b .
$$

Для визначення шуканих сталих величин $a$ і $b$ в (10) треба розв'язати систему рівнянь з урахуванням координат точок $\left(p_{i}, N_{\mathrm{immin}_{i}}\right)$ i $\left(p_{i+1}, N_{\mathrm{immin}_{i+1}}\right)$ :

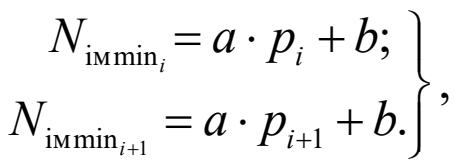

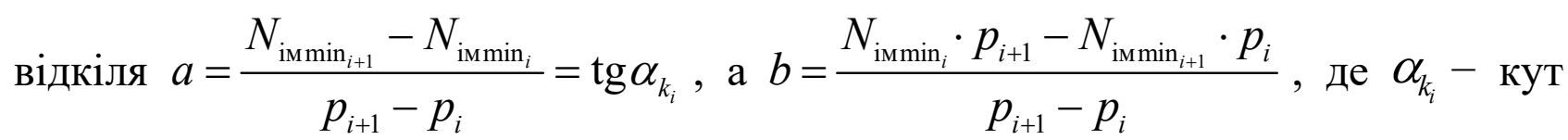
нахилу напрямної відрізка $H J$ до осі $p$.

При підстановці цих значень в (10) отримуємо залежність для функції натягу:

$$
N=\frac{N_{\mathrm{immin}_{i+1}}-N_{\text {iмmin }_{i}}}{p_{i+1}-p_{i}} \cdot p+\frac{N_{\text {immin }_{i}} \cdot p_{i+1}-N_{\text {iмmin }_{i+1}} \cdot p_{i}}{p_{i+1}-p_{i}}=p \cdot \operatorname{tg} \alpha_{k_{i}}+b,
$$

тоді рівняння відрізка $H J$ має остаточний вигляд:

$$
\omega_{k_{i}}=N-p \cdot \frac{N_{\mathrm{im} \min _{i+1}}-N_{\mathrm{ivmin}_{i}}}{p_{i+1}-p_{i}}-\frac{N_{\mathrm{immin}_{i}} \cdot p_{i+1}-N_{\mathrm{immin}_{i+1}} \cdot p_{i}}{p_{i+1}-p_{i}} .
$$


Координати точки $A\left(p_{A}, N_{A}\right)$ визначені в роботі [578]: $p_{A}=p-\frac{\left[p_{\max }\right]-\left[p_{\min }\right]}{2}$ i $\quad N_{A}=N-\frac{\left[N_{\max }\right]-\left[N_{\min }\right]}{2}$. Оскільки відрізок $A g$ перпендикулярний до $H J$, то його рівняння має вигляд:

$$
N=-p \cdot \operatorname{ctg} \alpha_{k_{i}}+d .
$$

Після підстановки в (14) координат точки $A\left(p_{A}, N_{A}\right)$ величина шуканої сталої:

$$
d=N_{A}+p_{A} \cdot \operatorname{ctg} \alpha_{k_{i}} .
$$

3 урахуванням тієї обставини, що точка $g$ є точкою перетину відрізів $A g$ i $H J$, тому шукані координати цієї точки $p_{g}$ і $N_{g}$ треба знайти в результаті розв'язання системи рівнянь:

$$
\left.\begin{array}{l}
N_{g}=p_{g} \cdot \operatorname{tg} \alpha_{k_{i}}+b \\
N_{g}=-p_{g} \cdot \operatorname{ctg} \alpha_{k_{i}}+d .
\end{array}\right\},
$$

Після математичних перетворень знаходимо координати точки $g$ :

$$
p_{g}=\frac{(d-b) \operatorname{tg} \alpha_{k_{i}}}{1+\operatorname{tg}^{2} \alpha_{k_{i}}} ; \quad N_{g}=\frac{b+d \cdot \operatorname{tg}^{2} \alpha_{k_{i}}}{1+\operatorname{tg}^{2} \alpha_{k_{i}}} .
$$

Рівняння відрізку $A g$ матиме вигляд:

$$
\omega_{A g}=N_{g}-N_{A}+\left(p_{g}-p_{A}\right) \cdot \frac{p_{i+1}-p_{i}}{N_{\text {immin }_{i+1}}-N_{\text {immin }_{i}}} .
$$

Величина радіусу $R$ і рівняння кола $\omega_{\square}$, де знаходиться ВЛЗРПП, мають аналітичний вигляд:

$$
R=\sqrt{\left(p_{g}-p_{A}\right)^{2}+\left(N_{g}-N_{A}\right)^{2}} ; \omega_{\square}=R^{2}-\left(p-p_{A}\right)^{2}-\left(N-N_{A}\right)^{2} .
$$

Рівняння ВЛЗРПП півкругової форми $\omega_{f g h}$ можна описати діагоналлю $u w 3$ iï рівнянням $\omega_{\text {, }}(3)$ та колом $\omega_{\square}$ за допомогою теорії $R$-функцій $[571,582]$ :

$$
\omega_{\text {fgh }}=\omega \wedge_{0} \omega \text {. }
$$


3 аналізу отриманого графіка (див. рис. 2) виплаває, що до точки $A$ в півкруговій ВЛЗРПП найбільш близькою буде точка $B$ відрізка $B L$ імовірнісного допуску посадки $H 7 / u 7$. Більша його частина $B X$ попадає у цей півкруг, що займає 45,58 мкм. Якщо розглядати посадки $H 8 / u 8$ i $H 7 / v 7$, то їх допуски займають довжини відповідно 41,26 мкм і 36,86 мкм, тобто як критерій вибору вважаємо найраціональнішою посадку $H 7 / u 7$. Рівняння раціональної множини $\omega_{i X}$ (для прикладу частини відрізка $B X$ посадки $H 7 / u 7$ ) згідно 3 теорією $R$-функцій має вигляд:

$$
\omega_{i X}=\omega_{i} \wedge_{0} \omega_{f g h}=\left(\omega_{i X_{p}} \vee_{0} \omega_{i X_{N}}\right) \wedge_{0}\left(\omega_{,} \wedge_{0} \omega_{\square}\right),
$$

де $\omega_{i}$ - аналітична формула $i$-ої придатної стандартної посадки [574]:

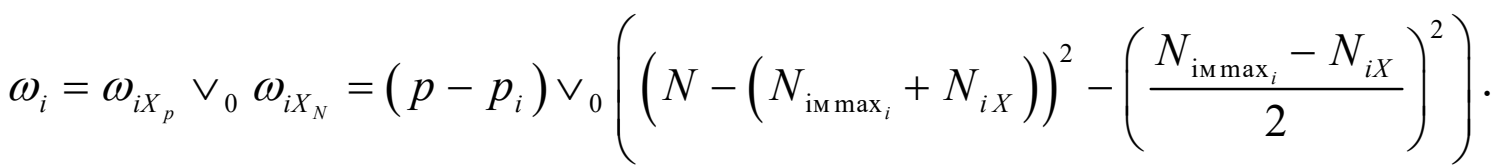

В отриманій формулі (22) $\omega_{i X_{p}}-$ вертикальна нескінчена пряма, яка збігається з напрямком частини відрізка імовірнісного допуску та є характерною для дійсного тиску $i$-ої стандартної посадки, що попала у ВЛЗРПП та ортогональна до координатної осі $p$; $\omega_{X_{N}}-$ ділянка, що обмежена кінцевою точкою $N_{\text {iмmax }_{i}}$ i точкою $N_{i X}$, яка відсікає відрізок імовірнісного допуску $i$-ої стандартної посадки півкруговою ВЛЗРПП. При цьому розглянутий відрізок розташований вздовж вертикальної нескінченої прямої $\omega_{i X_{p}}$.

Таким чином, авторами виконаних чисельно-аналітичних досліджень запропоновано i науково обгрунтовано ефективний системний підхід до автоматизованого розрахунку і вибору остаточного раціонального проектного рішення зі скінченої множини $m$-ої кількості допустимих альтернативних варіантів. Розглянутий метод прийнято як один 3 основних критеріїв вибору придатних посадок 3 натягом на основі побудови плоскої моделі області їх існування. В результаті дослідження описані основні елементи аналітичної моделі області існування раціональних посадок за допомогою математичного 
апарату теорії $R$-функцій, використання якого дозволило створити авторську комп'ютерну програму Interference Fit. Ця програма $є$ надійним і корисним інструментальним засобом досліджень для автоматизованого проектування посадок 3 натягом та дозволяє прискорити процес розрахунку i наочно відобразити математичну модель для вибору раціонального проектного рішення. 